\title{
Existence and Approximation of Attractive Points of the Widely More Generalized Hybrid Mappings in Hilbert Spaces
}

\author{
Sy-Ming Guu ${ }^{1}$ and Wataru Takahashi ${ }^{2}$ \\ ${ }^{1}$ Graduate Institute of Business and Management, College of Management, Chang-Gung University, Kwei-Shan, \\ Taoyuan Hsien 330, Taiwan \\ ${ }^{2}$ Department of Mathematical and Computing Sciences, Tokyo Institute of Technology, Tokyo 152-8552, Japan
}

Correspondence should be addressed to Sy-Ming Guu; iesmguu@mail.cgu.edu.tw

Received 30 January 2013; Accepted 5 June 2013

Academic Editor: Mohamed Amine Khamsi

Copyright (C) 2013 S.-M. Guu and W. Takahashi. This is an open access article distributed under the Creative Commons Attribution License, which permits unrestricted use, distribution, and reproduction in any medium, provided the original work is properly cited.

\begin{abstract}
We study the widely more generalized hybrid mappings which have been proposed to unify several well-known nonlinear mappings including the nonexpansive mappings, nonspreading mappings, hybrid mappings, and generalized hybrid mappings. Without the convexity assumption, we will establish the existence theorem and mean convergence theorem for attractive point of the widely more generalized hybrid mappings in a Hilbert space. Moreover, we prove a weak convergence theorem of Mann's type and a strong convergence theorem of Shimizu and Takahashi's type for such a wide class of nonlinear mappings in a Hilbert space. Our results can be viewed as a generalization of Kocourek, Takahashi and Yao, and Hojo and Takahashi where they studied the generalized hybrid mappings.
\end{abstract}

\section{Introduction}

Let $H$ be a real Hilbert space, and let $C$ be a nonempty subset of $H$. For a mapping $T: C \rightarrow H$, we denote by $F(T)$ and $A(T)$ the sets of fixed points and attractive points of $T$, respectively, that is,

(i) $F(T)=\{z \in C: T z=z\}$;

(ii) $A(T)=\{z \in H:\|T x-z\| \leq\|x-z\|, \forall x \in C\}$.

A mapping $T: C \rightarrow H$ is called nonexpansive [1] if $\| T x-$ $T y\|\leq\| x-y \|$ for all $x, y \in C$. A mapping $T: C \rightarrow H$ is called nonspreading [2], hybrid [3] if

$$
\begin{gathered}
2\|T x-T y\|^{2} \leq\|T x-y\|^{2}+\|T y-x\|^{2}, \\
3\|T x-T y\|^{2} \leq\|x-y\|^{2}+\|T x-y\|^{2}+\|T y-x\|^{2}
\end{gathered}
$$

for all $x, y \in C$, respectively; see also $[4,5]$. These three terms are independent, and they are deduced from the notion of firmly nonexpansive mapping in a Hilbert space; see [3]. A mapping $F: C \rightarrow H$ is said to be firmly nonexpansive if

$$
\|F x-F y\|^{2} \leq\langle x-y, F x-F y\rangle
$$

for all $x, y \in C$; see, for instance, Goebel and Kirk [6]. The class of nonspreading mappings was first defined in a strictly convex, smooth, and reflexive Banach space. The resolvents of a maximal monotone operator are nonspreading mappings; see [2] for more details. These three classes of nonlinear mappings are important in the study of the geometry of infinite dimensional spaces. Indeed, by using the fact that the resolvents of a maximal monotone operator are nonspreading mappings, Takahashi et al. [7] solved an open problem which is related to Ray's theorem [8] in the geometry of Banach spaces. Motivated by these mappings, Kocourek et al. [9] introduced a broad class of nonlinear mappings in a Hilbert space which covers nonexpansive mappings, nonspreading mappings, and hybrid mappings. A mapping $T: C \rightarrow H$ is said to be generalized hybrid if there exist $\alpha, \beta \in \mathbb{R}$ such that

$$
\begin{aligned}
\alpha \| T x & -T y\left\|^{2}+(1-\alpha)\right\| x-T y \|^{2} \\
& \leq \beta\|T x-y\|^{2}+(1-\beta)\|x-y\|^{2}
\end{aligned}
$$

for all $x, y \in C$, where $\mathbb{R}$ is the set of real numbers. We call such a mapping an $(\alpha, \beta)$-generalized hybrid mapping. 
An $(\alpha, \beta)$-generalized hybrid mapping is nonexpansive for $\alpha=1$ and $\beta=0$, nonspreading for $\alpha=2$ and $\beta=1$, and hybrid for $\alpha=3 / 2$ and $\beta=1 / 2$. They proved fixed point theorems for such mappings; see also Kohsaka and Takahashi [10] and Iemoto and Takahashi [4]. Moreover, they proved the following nonlinear ergodic theorem which generalizes Baillon's theorem [11].

Theorem 1 (see [9]). Let $H$ be a real Hilbert space, let $C$ be a nonempty closed convex subset of $H$, let $T$ be a generalized hybrid mapping from $C$ into itself with $F(T) \neq \emptyset$, and let $P$ be the metric projection of $H$ onto $F(T)$. Then for any $x \in C$,

$$
S_{n} x=\frac{1}{n} \sum_{k=0}^{n-1} T^{k} x
$$

converges weakly to $p \in F(T)$, where $p=\lim _{n \rightarrow \infty} P T^{n} x$.

We see that the set $C$ needs to be closed and convex in Theorem 1. As a contrast, Takahashi and Takeuchi [12] proved the following theorem which establishes the existence of attractive point and mean convergence property without the convexity assumption in a Hilbert space; see also Lin and Takahashi [13] and Takahashi et al. [14].

Theorem 2. Let $H$ be a real Hilbert space, and let $C$ be a nonempty subset of $H$. Let $T$ be a generalized hybrid mapping from $C$ into itself. Let $\left\{v_{n}\right\}$ and $\left\{b_{n}\right\}$ be sequences defined by

$$
v_{1} \in C, \quad v_{n+1}=T v_{n}, \quad b_{n}=\frac{1}{n} \sum_{k=1}^{n} v_{k}
$$

for all $n \in \mathbb{N}$. If $\left\{v_{n}\right\}$ is bounded, then the followings hold:

(1) $A(T)$ is nonempty, closed, and convex;

(2) $\left\{b_{n}\right\}$ converges weakly to $u_{0} \in A(T)$, where $u_{0}=$ $\lim _{n \rightarrow \infty} P_{A(T)} v_{n}$ and $P_{A(T)}$ is the metric projection of $H$ onto $A(T)$.

Very recently Kawasaki and Takahashi [15] introduced a class of nonlinear mappings in a Hilbert space which covers contractive mappings [16] and generalized hybrid mappings. A mapping $T: C \rightarrow H$ is called widely more generalized hybrid if there exist $\alpha, \beta, \gamma, \delta, \varepsilon, \zeta, \eta \in \mathbb{R}$ such that

$$
\begin{gathered}
\alpha\|T x-T y\|^{2}+\beta\|x-T y\|^{2}+\gamma\|T x-y\|^{2}+\delta\|x-y\|^{2} \\
\quad+\varepsilon\|x-T x\|^{2}+\zeta\|y-T y\|^{2}+\eta\|(x-T x)-(y-T y)\|^{2} \leq 0
\end{gathered}
$$

for any $x, y \in C$; see also Kawasaki and Takahashi [17].

A mapping $T: C \rightarrow H$ is called quasi-nonexpansive if $F(T) \neq \emptyset$ and $\|T x-y\| \leq\|x-y\|$ for all $x \in C$ and $y \in F(T)$. It is well known that if $C$ is closed and convex and $T: C \rightarrow H$ is quasi-nonexpansive, then $F(T)$ is closed and convex; see Itoh and Takahashi [18]. For a simpler proof of such a result in a Hilbert space, see, for example, [19]. A generalized hybrid mapping with a fixed point is quasinonexpansive. However, a widely more generalized hybrid mapping is not quasi-nonexpansive generally even if it has a fixed point. In [15], they proved fixed point theorems and nonlinear ergodic theorems of Baillon's type for such new mappings in a Hilbert space.

In this paper, motivated by these results, we establish the attractive point theorem and mean convergence theorem without the commonly required convexity for the widely more generalized hybrid mappings in a Hilbert space. Moreover, we prove a weak convergence theorem of Mann's type [20] and a strong convergence theorem of Shimizu and Takahashi's type [21] for such a class of nonlinear mappings in a Hilbert space which generalize Kocourek et al. [9] and Hojo and Takahashi [22] for generalized hybrid mappings, respectively.

\section{Preliminaries}

Throughout this paper, we denote by $\mathbb{N}$ the set of positive integers. Let $H$ be a real Hilbert space with inner product $\langle\cdot, \cdot\rangle$ and norm $\|\cdot\|$. We denote the strong convergence and the weak convergence of $\left\{x_{n}\right\}$ to $x \in H$ by $x_{n} \rightarrow x$ and $x_{n} \rightarrow x$, respectively. Let $A$ be a nonempty subset of $H$. We denote by $\overline{\mathrm{co}} A$ the closure of the convex hull of $A$. In a Hilbert space, it is known [1] that for any $x, y \in H$ and $\alpha \in \mathbb{R}$,

$$
\begin{gathered}
\|y\|^{2}-\|x\|^{2} \leq 2\langle y-x, y\rangle, \\
\|\alpha x+(1-\alpha) y\|^{2} \\
=\alpha\|x\|^{2}+(1-\alpha)\|y\|^{2}-\alpha(1-\alpha)\|x-y\|^{2} .
\end{gathered}
$$

Furthermore, we have that

$$
\begin{aligned}
2\langle x-y, z-w\rangle= & \|x-w\|^{2}+\|y-z\|^{2} \\
& -\|x-z\|^{2}-\|y-w\|^{2}
\end{aligned}
$$

for any $x, y, z, w \in H$.

Let $D$ be a nonempty closed convex subset of $H$ and $x \in H$. Then we know that there exists a unique nearest point $z \in D$ such that $\|x-z\|=\inf _{y \in D}\|x-y\|$. We denote such a correspondence by $z=P_{D} x$. The mapping $P_{D}$ is called the metric projection of $H$ onto $D$. It is known that $P_{D}$ is nonexpansive and

$$
\left\langle x-P_{D} x, P_{D} x-u\right\rangle \geq 0
$$

for any $x \in H$ and $u \in D$; see [1] for more details. For proving a nonlinear ergodic theorem in this paper, we also need the following lemma proved by Takahashi and Toyoda [23].

Lemma 3. Let $D$ be a nonempty closed convex subset of $H$. Let $P$ be the metric projection from $H$ onto $D$. Let $\left\{u_{n}\right\}$ be a sequence in $H$. If $\left\|u_{n+1}-u\right\| \leq\left\|u_{n}-u\right\|$ for any $u \in D$ and $n \in \mathbb{N}$, then $\left\{P u_{n}\right\}$ converges strongly to some $u_{0} \in D$.

To prove a strong convergence theorem in this paper, we need the following lemma. 
Lemma 4 (Aoyama et al. [24]). Let $\left\{s_{n}\right\}$ be a sequence of nonnegative real numbers, let $\left\{\alpha_{n}\right\}$ be a sequence of $[0,1]$ with $\sum_{n=1}^{\infty} \alpha_{n}=\infty$, let $\left\{\beta_{n}\right\}$ be a sequence of nonnegative real numbers with $\sum_{n=1}^{\infty} \beta_{n}<\infty$, and let $\left\{\gamma_{n}\right\}$ be a sequence of real numbers with $\limsup _{n \rightarrow \infty} \gamma_{n} \leq 0$. Suppose that

$$
s_{n+1} \leq\left(1-\alpha_{n}\right) s_{n}+\alpha_{n} \gamma_{n}+\beta_{n}
$$

for all $n=1,2, \ldots$. Then $\lim _{n \rightarrow \infty} s_{n}=0$.

Let $l^{\infty}$ be the Banach space of bounded sequences with supremum norm. Let $\mu$ be an element of $\left(l^{\infty}\right)^{*}$ (the dual space of $\left.l^{\infty}\right)$. Then we denote by $\mu(f)$ the value of $\mu$ at $f=$ $\left(x_{1}, x_{2}, x_{3}, \ldots\right) \in l^{\infty}$. Sometimes, we denote by $\mu_{n}\left(x_{n}\right)$ the value $\mu(f)$. A linear functional $\mu$ on $l^{\infty}$ is called a mean if $\mu(e)=\|\mu\|=1$, where $e=(1,1,1, \ldots)$. A mean $\mu$ is called a Banach limit on $l^{\infty}$ if $\mu_{n}\left(x_{n+1}\right)=\mu_{n}\left(x_{n}\right)$. We know that there exists a Banach limit on $l^{\infty}$. If $\mu$ is a Banach limit on $l^{\infty}$, then for $f=\left(x_{1}, x_{2}, x_{3}, \ldots\right) \in l^{\infty}$,

$$
\liminf _{n \rightarrow \infty} x_{n} \leq \mu_{n}\left(x_{n}\right) \leq \limsup _{n \rightarrow \infty} x_{n} .
$$

In particular, if $f=\left(x_{1}, x_{2}, x_{3}, \ldots\right) \in l^{\infty}$ and $x_{n} \rightarrow$ $a \in \mathbb{R}$, then we have $\mu(f)=\mu_{n}\left(x_{n}\right)=a$. See [25] for the proof of existence of a Banach limit and its other elementary properties. Using means and the Riesz theorem, we can obtain the following result; see $[25,26]$.

Lemma 5. Let $H$ be a real Hilbert space, let $\left\{x_{n}\right\}$ be a bounded sequence in $H$, and let $\mu$ be a mean on $l^{\infty}$. Then there exists a unique point $z_{0} \in \overline{\operatorname{co}}\left\{x_{n} \mid n \in \mathbb{N}\right\}$ such that

$$
\mu_{n}\left(\left\langle x_{n}, y\right\rangle\right)=\left\langle z_{0}, y\right\rangle
$$

for any $y \in H$.

The following result obtained by Takahashi and Takeuchi [12] is important in this paper.

Lemma 6. Let $H$ be a Hilbert space, let $C$ be a nonempty subset of $H$, and let $T$ be a mapping from $C$ into $H$. Then $A(T)$ is a closed and convex subset of $H$.

We also know the following result from [14].

Lemma 7. Let $H$ be a Hilbert space, let $C$ be a nonempty subset of $H$, and let $T$ be a quasi-nonexpansive mapping from $C$ into $H$. Then $A(T) \cap C=F(T)$.

\section{Attractive Point Theorems}

Let $H$ be a real Hilbert space, and let $C$ be a nonempty subset of $H$. Recall that a mapping $T$ from $C$ into $H$ is said to be widely more generalized hybrid [15] if there exist $\alpha, \beta, \gamma, \delta, \varepsilon, \zeta, \eta \in \mathbb{R}$ such that

$$
\begin{aligned}
& \alpha\|T x-T y\|^{2}+\beta\|x-T y\|^{2}+\gamma\|T x-y\|^{2}+\delta\|x-y\|^{2} \\
& \quad+\varepsilon\|x-T x\|^{2}+\zeta\|y-T y\|^{2}+\eta\|(x-T x)-(y-T y)\|^{2} \leq 0
\end{aligned}
$$

for any $x, y \in C$. Such a mapping $T$ is called $(\alpha, \beta, \gamma, \delta, \varepsilon, \zeta, \eta)$ widely more generalized hybrid. An $(\alpha, \beta, \gamma, \delta, \varepsilon, \zeta, \eta)$-widely more generalized hybrid mapping is generalized hybrid in the sense of Kocourek et al. [9] if $\alpha+\beta=-\gamma-\delta=1$ and $\varepsilon=\zeta=$ $\eta=0$. We first prove an attractive point theorem for widely more generalized hybrid mappings in a Hilbert space.

Theorem 8. Let $H$ be a real Hilbert space, let $C$ be a nonempty subset of $H$, and let $T$ be an $(\alpha, \beta, \gamma, \delta, \varepsilon, \zeta, \eta)$-widely more generalized hybrid mapping from $C$ into itself which satisfies either of the following conditions:

(1) $\alpha+\beta+\gamma+\delta \geq 0, \alpha+\gamma>0, \varepsilon+\eta \geq 0$ and $\zeta+\eta \geq 0$;

(2) $\alpha+\beta+\gamma+\delta \geq 0, \alpha+\beta>0, \zeta+\eta \geq 0$ and $\varepsilon+\eta \geq 0$.

Then $T$ has an attractive point if and only if there exists $z \in C$ such that $\left\{T^{n} z \mid n=0,1, \ldots\right\}$ is bounded.

Proof. Suppose that $T$ has an attractive point $z$. Then $\| T^{n+1} x-$ $z\|\leq\| T^{n} x-z \|$ for all $x \in C$ and $n \in \mathbb{N}$. Therefore $\left\{T^{n} z \mid n=\right.$ $0,1, \ldots\}$ is bounded.

Conversely suppose that there exists $z \in C$ such that $\left\{T^{n} z \mid n=0,1, \ldots\right\}$ is bounded. Since $T$ is an $(\alpha, \beta, \gamma, \delta, \varepsilon, \zeta, \eta)$-widely more generalized hybrid mapping from $C$ into itself, we obtain that

$$
\begin{aligned}
& \alpha\left\|T x-T^{n+1} z\right\|^{2}+\beta\left\|x-T^{n+1} z\right\|^{2}+\gamma\left\|T x-T^{n} z\right\|^{2} \\
& +\delta\left\|x-T^{n} z\right\|^{2}+\varepsilon\|x-T x\|^{2}+\zeta\left\|T^{n} z-T^{n+1} z\right\|^{2} \\
& +\eta\left\|(x-T x)-\left(T^{n} z-T^{n+1} z\right)\right\|^{2} \leq 0
\end{aligned}
$$

for any $n \in \mathbb{N} \cup\{0\}$ and $x \in C$. By (9) we obtain that

$$
\begin{aligned}
& \left\|(x-T x)-\left(T^{n} z-T^{n+1} z\right)\right\|^{2} \\
& =\|x-T x\|^{2}+\left\|T^{n} z-T^{n+1} z\right\|^{2}-2\left\langle x-T x, T^{n} z-T^{n+1} z\right\rangle \\
& =\|x-T x\|^{2}+\left\|T^{n} z-T^{n+1} z\right\|^{2}+\left\|x-T^{n} z\right\|^{2}+\left\|T x-T^{n+1} z\right\|^{2} \\
& \quad-\left\|x-T^{n+1} z\right\|^{2}-\left\|T x-T^{n} z\right\|^{2} .
\end{aligned}
$$

Thus we have that

$$
\begin{aligned}
& (\alpha+\eta)\left\|T x-T^{n+1} z\right\|^{2}+(\beta-\eta)\left\|x-T^{n+1} z\right\|^{2} \\
& \quad+(\gamma-\eta)\left\|T x-T^{n} z\right\|^{2}+(\delta+\eta)\left\|x-T^{n} z\right\|^{2} \\
& \quad+(\varepsilon+\eta)\|x-T x\|^{2}+(\zeta+\eta)\left\|T^{n} z-T^{n+1} z\right\|^{2} \leq 0 .
\end{aligned}
$$

From

$$
\begin{aligned}
& (\gamma-\eta)\left\|T x-T^{n} z\right\|^{2} \\
& =(\alpha+\gamma)\left(\|x-T x\|^{2}+\left\|x-T^{n} z\right\|^{2}-2\left\langle x-T x, x-T^{n} z\right\rangle\right) \\
& \quad-(\alpha+\eta)\left\|T x-T^{n} z\right\|^{2},
\end{aligned}
$$


we have that

$$
\begin{aligned}
& (\alpha+\eta)\left\|T x-T^{n+1} z\right\|^{2}+(\beta-\eta)\left\|x-T^{n+1} z\right\|^{2} \\
& +(\alpha+\gamma)\left(\|x-T x\|^{2}+\left\|x-T^{n} z\right\|^{2}-2\left\langle x-T x, x-T^{n} z\right\rangle\right) \\
& \quad-(\alpha+\eta)\left\|T x-T^{n} z\right\|^{2}+(\delta+\eta)\left\|x-T^{n} z\right\|^{2} \\
& \quad+(\varepsilon+\eta)\|x-T x\|^{2}+(\zeta+\eta)\left\|T^{n} z-T^{n+1} z\right\|^{2} \leq 0
\end{aligned}
$$

and hence

$$
\begin{aligned}
& (\alpha+\eta)\left(\left\|T x-T^{n+1} z\right\|^{2}-\left\|T x-T^{n} z\right\|^{2}\right) \\
& \quad+(\beta-\eta)\left\|x-T^{n+1} z\right\|^{2}-2(\alpha+\gamma)\left\langle x-T x, x-T^{n} z\right\rangle \\
& \quad+(\alpha+\gamma+\delta+\eta)\left\|x-T^{n} z\right\|^{2}+(\alpha+\gamma+\varepsilon+\eta)\|x-T x\|^{2} \\
& \quad+(\zeta+\eta)\left\|T^{n} z-T^{n+1} z\right\|^{2} \leq 0 .
\end{aligned}
$$

By $\alpha+\beta+\gamma+\delta \geq 0$, we have that

$$
-(\beta-\eta)=-(\beta+\delta)+\delta+\eta \leq \alpha+\gamma+\delta+\eta
$$

From this inequality and $\zeta+\eta \geq 0$ we obtain that

$$
\begin{aligned}
& (\alpha+\eta)\left(\left\|T x-T^{n+1} z\right\|^{2}-\left\|T x-T^{n} z\right\|^{2}\right) \\
& \quad+(\beta-\eta)\left(\left\|x-T^{n+1} z\right\|^{2}-\left\|x-T^{n} z\right\|^{2}\right) \\
& \quad-2(\alpha+\gamma)\left\langle x-T x, x-T^{n} z\right\rangle+(\alpha+\gamma+\varepsilon+\eta)\|x-T x\|^{2}
\end{aligned}
$$$$
\leq 0
$$

Applying a Banach limit $\mu$ to both sides of this inequality, we obtain that

$$
\begin{aligned}
& (\alpha+\eta)\left(\mu_{n}\left\|T x-T^{n+1} z\right\|^{2}-\mu_{n}\left\|T x-T^{n} z\right\|^{2}\right) \\
& +(\beta-\eta)\left(\mu_{n}\left\|x-T^{n+1} z\right\|^{2}-\mu_{n}\left\|x-T^{n} z\right\|^{2}\right) \\
& \quad-2(\alpha+\gamma) \mu_{n}\left\langle x-T x, x-T^{n} z\right\rangle \\
& \quad+(\alpha+\gamma+\varepsilon+\eta) \mu_{n}\|x-T x\|^{2} \leq 0,
\end{aligned}
$$

and hence

$$
\begin{aligned}
& -2(\alpha+\gamma) \mu_{n}\left\langle x-T x, x-T^{n} z\right\rangle+(\alpha+\gamma+\varepsilon+\eta)\|x-T x\|^{2} \\
& \quad \leq 0 .
\end{aligned}
$$

Since there exists $p \in H$ by Lemma 5 such that

$$
\mu_{n}\left\langle y, T^{n} z\right\rangle=\langle y, p\rangle
$$

for any $y \in H$, we obtain from (24) that

$$
-2(\alpha+\gamma)\langle x-T x, x-p\rangle+(\alpha+\gamma+\varepsilon+\eta)\|x-T x\|^{2} \leq 0 .
$$

We obtain from (9) that

$$
\begin{aligned}
& -(\alpha+\gamma)\left(\|x-p\|^{2}+\|T x-x\|^{2}-\|T x-p\|^{2}\right) \\
& +(\alpha+\gamma+\varepsilon+\eta)\|x-T x\|^{2} \leq 0,
\end{aligned}
$$

and hence

$$
-(\alpha+\gamma)\left(\|x-p\|^{2}-\|T x-p\|^{2}\right)+(\varepsilon+\eta)\|x-T x\|^{2} \leq 0 .
$$

Since $\varepsilon+\eta \geq 0$, we obtain that

$$
-(\alpha+\gamma)\left(\|x-p\|^{2}-\|T x-p\|^{2}\right) \leq 0 .
$$

Since $\alpha+\gamma>0$, we obtain that

$$
\|T x-p\|^{2} \leq\|x-p\|^{2} .
$$

This implies that $p \in H$ is an attractive point.

In the case of $\alpha+\beta+\gamma+\delta \geq 0, \alpha+\beta>0, \zeta+\eta \geq 0$, and $\varepsilon+\eta \geq 0$, we can obtain the result by replacing the variables $x$ and $y$. This completes the proof.

Using Theorem 8, we can show the following attractive point theorem for generalized hybrid mappings in a Hilbert space.

Theorem 9 (Takahashi and Takeuchi [12]). Let $H$ be a Hilbert space, let $C$ be a nonempty subset of $H$, and let $T$ be a generalized hybrid mapping from $C$ into $C$; that is, there exist real numbers $\alpha$ and $\beta$ such that

$$
\begin{aligned}
\alpha \| T x & -T y\left\|^{2}+(1-\alpha)\right\| x-T y \|^{2} \\
& \leq \beta\|T x-y\|^{2}+(1-\beta)\|x-y\|^{2}
\end{aligned}
$$

for all $x, y \in C$. Then $T$ has an attractive point if and only if there exists $z \in C$ such that $\left\{T^{n} z \mid n=0,1, \ldots\right\}$ is bounded.

Proof. An $(\alpha, \beta)$-generalized hybrid mapping $T$ is an $(\alpha, 1-$ $\alpha,-\beta,-(1-\beta), 0,0,0)$-widely more generalized hybrid mapping. Furthermore, the mapping satisfies the condition (2) in Theorem 8 , that is,

$$
\begin{gathered}
\alpha+(1-\alpha)-\beta-(1-\beta)=0 \geq 0, \quad \alpha+(1-\alpha)=1>0, \\
0+0 \geq 0, \quad 0+0 \geq 0 .
\end{gathered}
$$

Then we have the desired result from Theorem 8 .

\section{Nonlinear Ergodic Theorems}

In this section, using the technique developed by Takahashi [26], we prove a mean convergence theorem without convexity for widely more generalized hybrid mappings in a Hilbert space. Before proving the result, we need the following two lemmas. 
Lemma 10. Let $C$ be a nonempty subset of a real Hilbert space $H$. Let $T$ be an $(\alpha, \beta, \gamma, \delta, \varepsilon, \zeta, \eta)$-widely more generalized hybrid mapping from $C$ into itself such that $A(T) \neq \emptyset$. Suppose that it satisfies either of the following conditions:

(1) $\alpha+\beta+\gamma+\delta \geq 0, \alpha+\gamma+\varepsilon+\eta>0$ and $\zeta+\eta \geq 0$;

(2) $\alpha+\beta+\gamma+\delta \geq 0, \alpha+\beta+\zeta+\eta>0$ and $\varepsilon+\eta \geq 0$.

For any $x \in C$, define $S_{n} x=(1 / n) \sum_{k=1}^{n} T^{k} x$. Then, $\lim _{n \rightarrow \infty}\left\|S_{n} x-T S_{n} x\right\|=0$. In particular, if $C$ is bounded, then

$$
\lim _{n \rightarrow \infty} \sup _{x \in C}\left\|S_{n} x-T S_{n} x\right\|=0 .
$$

Proof. Let $x \in C$. Since $A(T)$ is nonempty, we obtain that

$$
\left\|T^{n+1} x-y\right\| \leq\left\|T^{n} x-y\right\|
$$

for any $n \in \mathbb{N} \cup\{0\}$ and $y \in A(T)$. Then we have that $\left\{T^{n} x\right\}$ is bounded. Since

$$
\left\|S_{n} x-y\right\| \leq \frac{1}{n} \sum_{k=0}^{n-1}\left\|T^{k} x-y\right\| \leq\|x-y\|
$$

for any $n \in \mathbb{N} \cup\{0\}$ and $y \in A(T),\left\{S_{n} x \mid n=0,1, \ldots\right\}$ is also bounded. Using $\alpha+\beta+\gamma+\delta \geq 0$ and $\zeta+\eta \geq 0$, as in the proof of Theorem 8 we have that

$$
\begin{aligned}
(\alpha+\eta) & \left(\left\|T z-T^{k+1} x\right\|^{2}-\left\|T z-T^{k} x\right\|^{2}\right) \\
& +(\beta-\eta)\left(\left\|z-T^{k+1} x\right\|^{2}-\left\|z-T^{k} x\right\|^{2}\right) \\
& -2(\alpha+\gamma)\left\langle z-T z, z-T^{k} x\right\rangle+(\alpha+\gamma+\varepsilon+\eta)\|z-T z\|^{2}
\end{aligned}
$$$$
\leq 0
$$

for any $k \in \mathbb{N} \cup\{0\}$ and $z \in C$. Summing up these inequalities with respect to $k=0,1, \ldots, n-1$ and dividing by $n$, we obtain that

$$
\begin{gathered}
\frac{\alpha+\eta}{n}\left(\left\|T z-T^{n} x\right\|^{2}-\|T z-x\|^{2}\right) \\
+\frac{\beta-\eta}{n}\left(\left\|z-T^{n} x\right\|^{2}-\|z-x\|^{2}\right) \\
-2(\alpha+\gamma)\left\langle z-T z, z-S_{n} x\right\rangle \\
+(\alpha+\gamma+\varepsilon+\eta)\|z-T z\|^{2} \leq 0 .
\end{gathered}
$$

Replacing $z$ by $S_{n} x$, we obtain that

$$
\begin{gathered}
\frac{\alpha+\eta}{n}\left(\left\|T S_{n} x-T^{n} x\right\|^{2}-\left\|T S_{n} x-x\right\|^{2}\right) \\
+\frac{\beta-\eta}{n}\left(\left\|S_{n} x-T^{n} x\right\|^{2}-\left\|S_{n} x-x\right\|^{2}\right) \\
+(\alpha+\gamma+\varepsilon+\eta)\left\|S_{n} x-T S_{n} x\right\|^{2} \leq 0 .
\end{gathered}
$$

Since $\left\{T S_{n} x\right\},\left\{S_{n} x\right\}$, and $\left\{T^{n} x\right\}$ are bounded, we have that

$$
(\alpha+\gamma+\varepsilon+\eta) \limsup _{n \rightarrow \infty}\left\|S_{n} x-T S_{n} x\right\| \leq 0 .
$$

Since $\alpha+\gamma+\varepsilon+\eta>0$, we have that $\lim _{n \rightarrow \infty}\left\|S_{n} x-T S_{n} x\right\|=0$. In particular, if $C$ is bounded, then

$$
\operatorname{limsupsup}_{n \rightarrow \infty}\left\|S_{n} x-T S_{n} x\right\| \leq 0,
$$

and hence $\lim _{n \rightarrow \infty} \sup _{x \in C}\left\|S_{n} x-T S_{n} x\right\|=0$.

Similarly, we can obtain the desired result for the case of $\alpha+\beta+\gamma+\delta \geq 0, \alpha+\beta+\zeta+\eta>0$, and $\varepsilon+\eta \geq 0$. This completes the proof.

Lemma 11. Let $H$ be a Hilbert space, and let $C$ be a nonempty subset of $H$. Let $T: C \rightarrow H$ be an $(\alpha, \beta, \gamma, \delta, \varepsilon, \zeta, \eta)$-widely more generalized hybrid mapping. Suppose that it satisfies either of the following conditions:

(1) $\alpha+\beta+\gamma+\delta \geq 0, \alpha+\gamma>0$ and $\varepsilon+\eta \geq 0$;

(2) $\alpha+\beta+\gamma+\delta \geq 0, \alpha+\beta>0$ and $\zeta+\eta \geq 0$.

If $x_{n} \rightarrow z$ and $x_{n}-T x_{n} \rightarrow 0$, then $z \in A(T)$.

Proof. Let $T: C \rightarrow H$ be an $(\alpha, \beta, \gamma, \delta, \varepsilon, \zeta, \eta)$-widely more generalized hybrid mapping, and suppose that $x_{n} \rightarrow z$ and $x_{n}-T x_{n} \rightarrow 0$. Replacing $x$ by $x_{n}$ in (14), we have that

$$
\begin{aligned}
& \alpha\left\|T x_{n}-T y\right\|^{2}+\beta\left\|x_{n}-T y\right\|^{2}+\gamma\left\|T x_{n}-y\right\|^{2}+\delta\left\|x_{n}-y\right\|^{2} \\
& \quad+\varepsilon\left\|x_{n}-T x_{n}\right\|^{2}+\zeta\|y-T y\|^{2}+\eta\left\|\left(x_{n}-T x_{n}\right)-(y-T y)\right\|^{2} \\
& \quad \leq 0 .
\end{aligned}
$$

From this inequality, we have that

$$
\begin{gathered}
\alpha\left(\left\|T x_{n}-x_{n}\right\|^{2}+\left\|x_{n}-T y\right\|^{2}+2\left\langle T x_{n}-x_{n}, x_{n}-T y\right\rangle\right) \\
+\beta\left\|x_{n}-T y\right\|^{2}+\gamma\left(\left\|T x_{n}-x_{n}\right\|^{2}+\left\|x_{n}-y\right\|^{2}\right. \\
\left.+2\left\langle T x_{n}-x_{n}, x_{n}-y\right\rangle\right) \\
+\delta\left\|x_{n}-y\right\|^{2}+\varepsilon\left\|x_{n}-T x_{n}\right\|^{2}+\zeta\|y-T y\|^{2} \\
+\eta\left\|\left(x_{n}-T x_{n}\right)-(y-T y)\right\|^{2} \leq 0 .
\end{gathered}
$$

We apply a Banach limit $\mu$ to both sides of this inequality. We have that

$$
\begin{gathered}
\alpha \mu_{n}\left(\left\|T x_{n}-x_{n}\right\|^{2}+\left\|x_{n}-T y\right\|^{2}+2\left\langle T x_{n}-x_{n}, x_{n}-T y\right\rangle\right) \\
+\beta \mu_{n}\left\|x_{n}-T y\right\|^{2}+\gamma \mu_{n}\left(\left\|T x_{n}-x_{n}\right\|^{2}+\left\|x_{n}-y\right\|^{2}\right. \\
\left.+2\left\langle T x_{n}-x_{n}, x_{n}-y\right\rangle\right) \\
+\delta \mu_{n}\left\|x_{n}-y\right\|^{2}+\varepsilon \mu_{n}\left\|x_{n}-T x_{n}\right\|^{2}+\zeta\|y-T y\|^{2} \\
+\eta \mu_{n}\left\|\left(x_{n}-T x_{n}\right)-(y-T y)\right\|^{2} \leq 0,
\end{gathered}
$$

and hence

$$
\begin{gathered}
\alpha \mu_{n}\left\|x_{n}-T y\right\|^{2}+\beta \mu_{n}\left\|x_{n}-T y\right\|^{2}+\gamma \mu_{n}\left\|x_{n}-y\right\|^{2}+\delta \mu_{n}\left\|x_{n}-y\right\|^{2} \\
+\zeta\|y-T y\|^{2}+\eta \mu_{n}\left\|\left(x_{n}-T x_{n}\right)-(y-T y)\right\|^{2} \leq 0 .
\end{gathered}
$$


Thus we have

$$
\begin{aligned}
& (\alpha+\beta) \mu_{n}\left\|x_{n}-T y\right\|^{2}+(\gamma+\delta) \mu_{n}\left\|x_{n}-y\right\|^{2} \\
& +(\zeta+\eta)\|y-T y\|^{2} \leq 0 .
\end{aligned}
$$

From $\left\|x_{n}-T y\right\|^{2}=\left\|x_{n}-y\right\|^{2}+\|y-T y\|^{2}+2\left\langle x_{n}-y, y-T y\right\rangle$, we also have

$$
\begin{aligned}
& (\alpha+\beta)\left(\mu_{n}\left\|x_{n}-y\right\|^{2}+\|y-T y\|^{2}+2 \mu_{n}\left\langle x_{n}-y, y-T y\right\rangle\right) \\
& +(\gamma+\delta) \mu_{n}\left\|x_{n}-y\right\|^{2}+(\zeta+\eta)\|y-T y\|^{2} \leq 0 .
\end{aligned}
$$

From $\alpha+\beta+\gamma+\delta \geq 0$ we obtain that

$$
\begin{aligned}
& (\alpha+\beta)\|y-T y\|^{2}+2(\alpha+\beta) \mu_{n}\left\langle x_{n}-y, y-T y\right\rangle \\
& +(\zeta+\eta)\|y-T y\|^{2} \leq 0,
\end{aligned}
$$

and hence

$$
\begin{aligned}
& (\alpha+\beta+\zeta+\eta)\|y-T y\|^{2}+2(\alpha+\beta) \mu_{n}\left\langle x_{n}-y, y-T y\right\rangle \\
& \quad \leq 0
\end{aligned}
$$

Since $x_{n} \rightarrow z$, we have that

$$
\begin{aligned}
& (\alpha+\beta+\zeta+\eta)\|y-T y\|^{2}+2(\alpha+\beta)\langle z-y, y-T y\rangle \\
& \quad \leq 0 .
\end{aligned}
$$

Using (9), we have that

$$
\begin{aligned}
& (\alpha+\beta+\zeta+\eta)\|y-T y\|^{2} \\
& \quad+(\alpha+\beta)\left(\|z-T y\|^{2}-\|z-y\|^{2}-\|y-T y\|^{2}\right) \leq 0
\end{aligned}
$$

and hence

$$
(\zeta+\eta)\|y-T y\|^{2}+(\alpha+\beta)\left(\|z-T y\|^{2}-\|z-y\|^{2}\right) \leq 0 .
$$

Since $\alpha+\beta>0$ and $\zeta+\eta \geq 0$, we have that

$$
\|z-T y\|^{2}-\|z-y\|^{2} \leq 0
$$

for all $y \in C$. This implies that $z \in A(T)$.

Similarly, we can obtain the desired result for the case of $\alpha+\beta+\gamma+\delta \geq 0, \alpha+\gamma>0$, and $\varepsilon+\eta \geq 0$. This completes the proof.

Now we have the following nonlinear ergodic theorem for widely more generalized hybrid mappings in a Hilbert space.

Theorem 12. Let $H$ be a real Hilbert space, let $C$ be a nonempty subset of $H$, let $T$ be an $(\alpha, \beta, \gamma, \delta, \varepsilon, \zeta, \eta)$-widely more generalized hybrid mapping from $C$ into itself such that
$A(T) \neq \emptyset$, and let $P$ be the metric projection of $H$ onto $A(T)$. Suppose that $T$ satisfies either of the conditions:

(1) $\alpha+\beta+\gamma+\delta \geq 0, \alpha+\gamma>0, \varepsilon+\eta \geq 0$ and $\zeta+\eta \geq 0$;

(2) $\alpha+\beta+\gamma+\delta \geq 0, \alpha+\beta>0, \zeta+\eta \geq 0$ and $\varepsilon+\eta \geq 0$.

Then for any $x \in C$,

$$
S_{n} x=\frac{1}{n} \sum_{k=0}^{n-1} T^{k} x
$$

is weakly convergent to an attractive point $p$ of $T$, where $p=$ $\lim _{n \rightarrow \infty} P T^{n} x$.

Proof. Let $x \in C$. Since $A(T)$ is nonempty, we obtain that

$$
\left\|T^{n+1} x-y\right\| \leq\left\|T^{n} x-y\right\|
$$

for any $n \in \mathbb{N} \cup\{0\}$ and $y \in A(T)$. Thus $\left\{T^{n} x\right\}$ is bounded. Since

$$
\left\|S_{n} x-y\right\| \leq \frac{1}{n} \sum_{k=0}^{n-1}\left\|T^{k} x-y\right\| \leq\|x-y\|
$$

for any $n \in \mathbb{N} \cup\{0\}$ and $y \in A(T),\left\{S_{n} x \mid n=0,1, \ldots\right\}$ is also bounded. Therefore there exists a strictly increasing sequence $\left\{n_{i}\right\}$ and $p \in H$ such that $\left\{S_{n_{i}} x \mid i=0,1, \ldots\right\}$ converges weakly to $p$. Using $\alpha+\beta+\gamma+\delta \geq 0, \alpha+\gamma>0, \varepsilon+\eta \geq 0$, and $\zeta+\eta \geq 0$, we have from Lemma 10 that

$$
\lim _{n \rightarrow \infty}\left\|S_{n} x-T S_{n} x\right\|=0 .
$$

We have from Lemma 11 that $p \in A(T)$. Since $A(T)$ is closed and convex from Lemma 6 , the metric projection $P$ from $H$ onto $A(T)$ is well defined. By Lemma 3, there exists $q \in A(T)$ such that $\left\{P T^{n} x \mid n=0,1, \ldots\right\}$ converges strongly to $q$. To complete the proof, we show that $q=p$. Note that the metric projection $P$ satisfies

$$
\langle z-P z, P z-u\rangle \geq 0
$$

for any $z \in H$ and for any $u \in A(T)$; see [25]. Therefore

$$
\left\langle T^{k} x-P T^{k} x, P T^{k} x-y\right\rangle \geq 0
$$

for any $k \in \mathbb{N} \cup\{0\}$ and $y \in A(T)$. Since $P$ is the metric projection from $H$ onto $A(T)$ and $P T^{n-1} x \in A(T)$, we obtain that

$$
\begin{aligned}
\left\|T^{n} x-P T^{n} x\right\| & \leq\left\|T^{n} x-P T^{n-1} x\right\| \\
& \leq\left\|T^{n-1} x-P T^{n-1} x\right\| .
\end{aligned}
$$

That is, $\left\{\left\|T^{n} x-P T^{n} x\right\| \mid n=0,1, \ldots\right\}$ is nonincreasing. Therefore we obtain

$$
\begin{aligned}
\left\langle T^{k} x-P T^{k} x, y-q\right\rangle & \leq\left\langle T^{k} x-P T^{k} x, P T^{k} x-q\right\rangle \\
& \leq\left\|T^{k} x-P T^{k} x\right\| \cdot\left\|P T^{k} x-q\right\| \\
& \leq\|x-P x\| \cdot\left\|P T^{k} x-q\right\| .
\end{aligned}
$$


Summing up these inequalities with respect to $k=0,1, \ldots$, $n-1$ and dividing by $n$, we obtain

$$
\left\langle S_{n} x-\frac{1}{n} \sum_{k=0}^{n-1} P T^{k} x, y-q\right\rangle \leq \frac{\|x-P x\|^{n-1}}{n} \sum_{k=0}\left\|P T^{k} x-q\right\| .
$$

Since $\left\{S_{n_{i}} x \mid i=0,1, \ldots\right\}$ converges weakly to $p$ and $\left\{P T^{n} x \mid\right.$ $n=0,1, \ldots\}$ converges strongly to $q$, we obtain that

$$
\langle p-q, y-q\rangle \leq 0
$$

Putting $y=p$, we obtain

$$
\|p-q\|^{2} \leq 0
$$

and hence $q=p$. This completes the proof.

Similarly, we can obtain the desired result for the case of $\alpha+\beta+\gamma+\delta \geq 0, \alpha+\beta>0, \zeta+\eta>0$, and $\varepsilon+\eta \geq 0$.

As the proof of Theorem 9, we can prove Takahashi and Takeuchi's mean convergence theorem for generalized hybrid mappings in a Hilbert space.

Theorem 13. Let $H$ be a Hilbert space, let $C$ be a nonempty subset of $H$, and let $T$ be a generalized hybrid mapping from $C$ into itself; that is, there exist $\alpha, \beta \in \mathbb{R}$ such that

$$
\begin{aligned}
\alpha \| T x & -T y\left\|^{2}+(1-\alpha)\right\| x-T y \|^{2} \\
& \leq \beta\|T x-y\|^{2}+(1-\beta)\|x-y\|^{2}
\end{aligned}
$$

for all $x, y \in C$. Suppose that $A(T) \neq \emptyset$, and let $P$ be the metric projection from $H$ onto $A(T)$. Then for any $x \in C$,

$$
S_{n} x=\frac{1}{n} \sum_{k=0}^{n-1} T^{k} x
$$

converges weakly to $p \in A(T)$, where $p=\lim _{n \rightarrow \infty} P T^{n} x$.

\section{Weak Convergence Theorems of Mann's Type}

In this section, we prove a weak convergence theorem of Mann's type [20] for widely more generalized hybrid mappings in a Hilbert space by using Lemma 11 and the technique developed by Ibaraki and Takahashi $[27,28]$.

Theorem 14. Let $H$ be a Hilbert space, and let $C$ be a convex subset of $H$. Let $T: C \rightarrow C$ be a widely more generalized hybrid mapping with $A(T) \neq \emptyset$ such that it satisfies either of the conditions:

(1) $\alpha+\beta+\gamma+\delta \geq 0, \alpha+\gamma>0$ and $\varepsilon+\eta \geq 0$;

(2) $\alpha+\beta+\gamma+\delta \geq 0, \alpha+\beta>0$ and $\zeta+\eta \geq 0$.

Let $P$ be the metric projection of $H$ onto $A(T)$. Let $\left\{\alpha_{n}\right\}$ be a sequence of real numbers such that $0 \leq \alpha_{n} \leq 1$ and $\liminf _{n \rightarrow \infty} \alpha_{n}\left(1-\alpha_{n}\right)>0$. Suppose that $\left\{x_{n}\right\}$ is the sequence generated by $x_{1}=x \in C$ and

$$
x_{n+1}=\alpha_{n} x_{n}+\left(1-\alpha_{n}\right) T x_{n}, \quad n \in \mathbb{N} .
$$

Then $\left\{x_{n}\right\}$ converges weakly to $v \in A(T)$, where $v=$ $\lim _{n \rightarrow \infty} P x_{n}$.

Proof. Let $z \in A(T)$. We have that

$$
\begin{aligned}
\| x_{n+1} & -z \|^{2} \\
& =\left\|\alpha_{n} x_{n}+\left(1-\alpha_{n}\right) T x_{n}-z\right\|^{2} \\
& \leq \alpha_{n}\left\|x_{n}-z\right\|^{2}+\left(1-\alpha_{n}\right)\left\|T x_{n}-z\right\|^{2} \\
& \leq \alpha_{n}\left\|x_{n}-z\right\|^{2}+\left(1-\alpha_{n}\right)\left\|x_{n}-z\right\|^{2} \\
& =\left\|x_{n}-z\right\|^{2}
\end{aligned}
$$

for all $n \in \mathbb{N}$. Hence $\lim _{n \rightarrow \infty}\left\|x_{n}-z\right\|^{2}$ exists. Then $\left\{x_{n}\right\}$ is bounded. We also have from (8) that

$$
\begin{aligned}
& \left\|x_{n+1}-z\right\|^{2}=\left\|\alpha_{n} x_{n}+\left(1-\alpha_{n}\right) T x_{n}-z\right\|^{2} \\
& \quad=\alpha_{n}\left\|x_{n}-z\right\|^{2}+\left(1-\alpha_{n}\right)\left\|T x_{n}-z\right\|^{2}-\alpha_{n}\left(1-\alpha_{n}\right)\left\|T x_{n}-x_{n}\right\|^{2} \\
& \quad \leq \alpha_{n}\left\|x_{n}-z\right\|^{2}+\left(1-\alpha_{n}\right)\left\|x_{n}-z\right\|^{2}-\alpha_{n}\left(1-\alpha_{n}\right)\left\|T x_{n}-x_{n}\right\|^{2} \\
& \quad=\left\|x_{n}-z\right\|^{2}-\alpha_{n}\left(1-\alpha_{n}\right)\left\|T x_{n}-x_{n}\right\|^{2} .
\end{aligned}
$$

Thus we have

$$
\alpha_{n}\left(1-\alpha_{n}\right)\left\|T x_{n}-x_{n}\right\|^{2} \leq\left\|x_{n}-z\right\|^{2}-\left\|x_{n+1}-z\right\|^{2} .
$$

Since $\lim _{n \rightarrow \infty}\left\|x_{n}-z\right\|^{2}$ exists and $\liminf _{n \rightarrow \infty} \alpha_{n}\left(1-\alpha_{n}\right)>0$, we have that

$$
\left\|T x_{n}-x_{n}\right\| \longrightarrow 0 .
$$

Since $\left\{x_{n}\right\}$ is bounded, there exists a subsequence $\left\{x_{n_{i}}\right\}$ of $\left\{x_{n}\right\}$ such that $x_{n_{i}} \rightarrow v$. By Lemma 11 and (70), we obtain that $v \in A(T)$. Let $\left\{x_{n_{i}}\right\}$ and $\left\{x_{n_{j}}\right\}$ be two subsequences of $\left\{x_{n}\right\}$ such that $x_{n_{i}} \rightarrow v_{1}$ and $x_{n_{j}} \rightarrow v_{2}$. To complete the proof, we show $v_{1}=v_{2}$. We know that $v_{1}, v_{2} \in A(T)$, and hence $\lim _{n \rightarrow \infty}\left\|x_{n}-v_{1}\right\|^{2}$ and $\lim _{n \rightarrow \infty}\left\|x_{n}-v_{2}\right\|^{2}$ exist. Put

$$
a=\lim _{n \rightarrow \infty}\left(\left\|x_{n}-v_{1}\right\|^{2}-\left\|x_{n}-v_{2}\right\|^{2}\right) .
$$

Note that for $n=1,2, \ldots$,

$$
\left\|x_{n}-v_{1}\right\|^{2}-\left\|x_{n}-v_{2}\right\|^{2}=2\left\langle x_{n}, v_{2}-v_{1}\right\rangle+\left\|v_{1}\right\|^{2}-\left\|v_{2}\right\|^{2} \text {. }
$$

From $x_{n_{i}} \rightarrow v_{1}$ and $x_{n_{j}} \rightarrow v_{2}$, we have

$$
\begin{aligned}
& a=2\left\langle v_{1}, v_{2}-v_{1}\right\rangle+\left\|v_{1}\right\|^{2}-\left\|v_{2}\right\|^{2}, \\
& a=2\left\langle v_{2}, v_{2}-v_{1}\right\rangle+\left\|v_{1}\right\|^{2}-\left\|v_{2}\right\|^{2} .
\end{aligned}
$$


Combining (73) and (74), we obtain $0=2\left\langle v_{2}-v_{1}, v_{2}-v_{1}\right\rangle$. Thus we obtain $v_{2}=v_{1}$. This implies that $\left\{x_{n}\right\}$ converges weakly to an element $v \in A(T)$. Since $\left\|x_{n+1}-z\right\| \leq\left\|x_{n}-z\right\|$ for all $z \in A(T)$ and $n \in \mathbb{N}$, we obtain from Lemma 3 that $\left\{P x_{n}\right\}$ converges strongly to an element $p \in A(T)$. On the other hand, we have from the property of $P$ that

$$
\left\langle x_{n}-P x_{n}, P x_{n}-u\right\rangle \geq 0
$$

for all $u \in A(T)$ and $n \in \mathbb{N}$. Since $x_{n} \rightarrow v$ and $P x_{n} \rightarrow p$, we obtain

$$
\langle v-p, p-u\rangle \geq 0
$$

for all $u \in A(T)$. Putting $u=v$, we obtain $p=v$. This means $v=\lim _{n \rightarrow \infty} P x_{n}$. This completes the proof.

Using Theorem 14, we can show the following weak convergence theorem of Mann's type for generalized hybrid mappings in a Hilbert space.

Theorem 15 (Kocourek et al. [9]). Let $H$ be a Hilbert space, and let $C$ be a closed convex subset of $H$. Let $T: C \rightarrow C$ be a generalized hybrid mapping with $F(T) \neq \emptyset$. Let $\left\{\alpha_{n}\right\}$ be a sequence of real numbers such that $0 \leq \alpha_{n} \leq 1$ and $\liminf _{n \rightarrow \infty} \alpha_{n}\left(1-\alpha_{n}\right)>0$. Suppose $\left\{x_{n}\right\}$ is the sequence generated by $x_{1}=x \in C$ and

$$
x_{n+1}=\alpha_{n} x_{n}+\left(1-\alpha_{n}\right) T x_{n}, \quad n \in \mathbb{N} .
$$

Then the sequence $\left\{x_{n}\right\}$ converges weakly to an element $v \in$ $F(T)$.

Proof. As in the proof of Theorem 9, a generalized hybrid mapping is a widely more generalized hybrid mapping. Since $\left\{x_{n}\right\} \subset C$ and $C$ is closed and convex, we have from Theorem 14 that $v \in A(T) \cap C$. A generalized hybrid mapping with $F(T) \neq \emptyset$ is quasi-nonexpansive, we have from Lemma 7 that $A(T) \cap C=F(T)$. Thus $\left\{x_{n}\right\}$ converges weakly to an element $v \in F(T)$.

\section{Strong Convergence Theorem}

In this section, using an idea of mean convergence by Shimizu and Takahashi $[21,29]$, we prove the following strong convergence theorem for widely more generalized hybrid mappings in a Hilbert space.

Theorem 16. Let $C$ be a nonempty convex subset of a real Hilbert space $H$. Let $T$ be a widely more generalized hybrid mapping of $C$ into itself with $A(T) \neq \emptyset$ such that it satisfies either of the following conditions:

(1) $\alpha+\beta+\gamma+\delta \geq 0, \alpha+\gamma>0, \varepsilon+\eta \geq 0$ and $\zeta+\eta \geq 0$;

(2) $\alpha+\beta+\gamma+\delta \geq 0, \alpha+\beta>0, \zeta+\eta \geq 0$ and $\varepsilon+\eta \geq 0$.

Let $u \in C$, and define sequences $\left\{x_{n}\right\}$ and $\left\{z_{n}\right\}$ in $C$ as follows: $x_{1}=x \in C$ and

$$
\begin{gathered}
x_{n+1}=\alpha_{n} u+\left(1-\alpha_{n}\right) z_{n}, \\
z_{n}=\frac{1}{n} \sum_{k=0}^{n-1} T^{k} x_{n}
\end{gathered}
$$

for all $n=1,2, \ldots$, where $0 \leq \alpha_{n} \leq 1, \alpha_{n} \rightarrow 0$ and $\sum_{n=1}^{\infty} \alpha_{n}=$ $\infty$. If $A(T)$ is nonempty, then $\left\{x_{n}\right\}$ and $\left\{z_{n}\right\}$ converge strongly to $\mathrm{Pu}$, where $P$ is the metric projection of $H$ onto $A(T)$.

Proof. Since $T: C \rightarrow C$ is a widely more generalized hybrid mapping, there exist $\alpha, \beta, \gamma, \delta, \varepsilon, \zeta, \eta \in \mathbb{R}$ such that

$$
\begin{aligned}
& \alpha\|T x-T y\|^{2}+\beta\|x-T y\|^{2}+\gamma\|T x-y\|^{2}+\delta\|x-y\|^{2} \\
& \quad+\varepsilon\|x-T x\|^{2}+\zeta\|y-T y\|^{2}+\eta\|(x-T x)-(y-T y)\|^{2} \leq 0
\end{aligned}
$$

for any $x, y \in C$. Since $A(T) \neq \emptyset$, we have that for all $q \in A(T)$ and $n=1,2,3, \ldots$,

$$
\begin{aligned}
\left\|z_{n}-q\right\| & =\left\|\frac{1}{n} \sum_{k=0}^{n-1} T^{k} x_{n}-q\right\| \leq \frac{1}{n} \sum_{k=0}^{n-1}\left\|T^{k} x_{n}-q\right\| \\
& \leq \frac{1}{n} \sum_{k=0}^{n-1}\left\|x_{n}-q\right\|=\left\|x_{n}-q\right\| .
\end{aligned}
$$

Then we have

$$
\begin{aligned}
\left\|x_{n+1}-q\right\| & =\left\|\alpha_{n} u+\left(1-\alpha_{n}\right) z_{n}-q\right\| \\
& \leq \alpha_{n}\|u-q\|+\left(1-\alpha_{n}\right)\left\|z_{n}-q\right\| \\
& \leq \alpha_{n}\|u-q\|+\left(1-\alpha_{n}\right)\left\|x_{n}-q\right\| .
\end{aligned}
$$

Hence, by induction, we obtain

$$
\left\|x_{n}-q\right\| \leq \max \{\|u-q\|,\|x-q\|\}
$$

for all $n \in \mathbb{N}$. This implies that $\left\{x_{n}\right\}$ and $\left\{z_{n}\right\}$ are bounded. Since $\left\|T^{n} x_{n}-q\right\| \leq\left\|x_{n}-q\right\|$, we have also that $\left\{T^{n} x_{n}\right\}$ is bounded.

Let $n \in \mathbb{N}$. Using $\alpha+\beta+\gamma+\delta \geq 0$ and $\zeta+\eta \geq 0$, as in the proof of Theorem 8 we have that

$$
\begin{aligned}
& (\alpha+\eta)\left(\left\|T z-T^{k+1} x_{n}\right\|^{2}-\left\|T z-T^{k} x_{n}\right\|^{2}\right) \\
& +(\beta-\eta)\left(\left\|z-T^{k+1} x_{n}\right\|^{2}-\left\|z-T^{k} x_{n}\right\|^{2}\right) \\
& \quad-2(\alpha+\gamma)\left\langle z-T z, z-T^{k} x_{n}\right\rangle+(\alpha+\gamma+\varepsilon+\eta)\|z-T z\|^{2}
\end{aligned}
$$$$
\leq 0
$$

for any $k \in \mathbb{N} \cup\{0\}$ and $z \in C$. Summing up these inequalities with respect to $k=0,1, \ldots, n-1$ and dividing by $n$, we obtain that

$$
\begin{aligned}
& \frac{\alpha+\eta}{n}\left(\left\|T z-T^{n} x_{n}\right\|^{2}-\left\|T z-x_{n}\right\|^{2}\right) \\
& \quad+\frac{\beta-\eta}{n}\left(\left\|z-T^{n} x_{n}\right\|^{2}-\left\|z-x_{n}\right\|^{2}\right) \\
& \quad-2(\alpha+\gamma)\left\langle z-T z, z-z_{n}\right\rangle+(\alpha+\gamma+\varepsilon+\eta)\|z-T z\|^{2}
\end{aligned}
$$

$\leq 0$. 
Since $\left\{z_{n}\right\}$ is bounded, there exists a subsequence $\left\{z_{n_{i}}\right\}$ of $\left\{z_{n}\right\}$ such that $z_{n_{i}} \rightarrow w \in H$. Replacing $n$ by $n_{i}$, we have that

$$
\begin{aligned}
& \frac{\alpha+\eta}{n_{i}}\left(\left\|T z-T^{n_{i}} x_{n_{i}}\right\|^{2}-\left\|T z-x_{n_{i}}\right\|^{2}\right) \\
& \quad+\frac{\beta-\eta}{n_{i}}\left(\left\|z-T^{n_{i}} x_{n_{i}}\right\|^{2}-\left\|z-x_{n_{i}}\right\|^{2}\right) \\
& \quad-2(\alpha+\gamma)\left\langle z-T z, z-z_{n_{i}}\right\rangle+(\alpha+\gamma+\varepsilon+\eta)\|z-T z\|^{2} \leq 0 .
\end{aligned}
$$

Since $\left\{x_{n}\right\}$ and $\left\{T^{n} x_{n}\right\}$ are bounded, we have that

$$
-2(\alpha+\gamma)\langle z-T z, z-w\rangle+(\alpha+\gamma+\varepsilon+\eta)\|z-T z\|^{2} \leq 0
$$

as $i \rightarrow \infty$. Using (9), we have that

$$
\begin{aligned}
& (\alpha+\gamma+\varepsilon+\eta)\|z-T z\|^{2} \\
& \quad+(\alpha+\gamma)\left(\|w-T z\|^{2}-\|w-z\|^{2}-\|z-T z\|^{2}\right) \leq 0,
\end{aligned}
$$

and hence

$$
(\varepsilon+\eta)\|z-T z\|^{2}+(\alpha+\gamma)\left(\|w-T z\|^{2}-\|w-z\|^{2}\right) \leq 0 .
$$

Since $\alpha+\gamma>0$ and $\varepsilon+\eta \geq 0$, we have that

$$
\|w-T z\|^{2}-\|w-z\|^{2} \leq 0
$$

for all $z \in C$. This implies that $w \in A(T)$.

On the other hand, since $x_{n+1}-z_{n}=\alpha_{n}\left(u-z_{n}\right),\left\{z_{n}\right\}$ is bounded, and $\alpha_{n} \rightarrow 0$, we have $\lim _{n \rightarrow \infty}\left\|x_{n+1}-z_{n}\right\|=0$. Let us show

$$
\limsup _{n \rightarrow \infty}\left\langle u-P u, x_{n+1}-P u\right\rangle \leq 0 \text {. }
$$

We may assume without loss of generality that there exists a subsequence $\left\{x_{n_{i}+1}\right\}$ of $\left\{x_{n+1}\right\}$ such that

$$
\limsup _{n \rightarrow \infty}\left\langle u-P u, x_{n+1}-P u\right\rangle=\lim _{i \rightarrow \infty}\left\langle u-P u, x_{n_{i}+1}-P u\right\rangle
$$

and $x_{n_{i}+1} \rightarrow v$. From $\left\|x_{n+1}-z_{n}\right\| \rightarrow 0$, we have $z_{n_{i}} \rightarrow v$. From the above argument, we have $v \in A(T)$. Since $P$ is the metric projection of $H$ onto $A(T)$, we have

$$
\lim _{i \rightarrow \infty}\left\langle u-P u, x_{n_{i}+1}-P u\right\rangle=\langle u-P u, v-P u\rangle \leq 0 .
$$

This implies

$$
\limsup _{n \rightarrow \infty}\left\langle u-P u, x_{n+1}-P u\right\rangle \leq 0 .
$$

Since $x_{n+1}-P u=\left(1-\alpha_{n}\right)\left(z_{n}-P u\right)+\alpha_{n}(u-P u)$, from $(7)$ and (80) we have

$$
\begin{aligned}
\left\|x_{n+1}-P u\right\|^{2} & =\left\|\left(1-\alpha_{n}\right)\left(z_{n}-P u\right)+\alpha_{n}(u-P u)\right\|^{2} \\
& \leq\left(1-\alpha_{n}\right)^{2}\left\|z_{n}-P u\right\|^{2}+2 \alpha_{n}\left\langle u-P u, x_{n+1}-P u\right\rangle \\
& \leq\left(1-\alpha_{n}\right)\left\|x_{n}-P u\right\|^{2}+2 \alpha_{n}\left\langle u-P u, x_{n+1}-P u\right\rangle .
\end{aligned}
$$

Putting $s_{n}=\left\|x_{n}-P u\right\|^{2}, \beta_{n}=0$, and $\gamma_{n}=2\left\langle u-P u, x_{n+1}-P u\right\rangle$ in Lemma 4 , we have from $\sum_{n=1}^{\infty} \alpha_{n}=\infty$ and (93) that

$$
\lim _{n \rightarrow \infty}\left\|x_{n}-P u\right\|=0 \text {. }
$$

By $\lim _{n \rightarrow \infty}\left\|x_{n+1}-z_{n}\right\|=0$, we also obtain $z_{n} \rightarrow P u$ as $n \rightarrow$ $\infty$.

Similarly, we can obtain the desired result for the case of $\alpha+\beta+\gamma+\delta \geq 0, \alpha+\beta>0, \zeta+\eta \geq 0$, and $\varepsilon+\eta \geq 0$.

Using Theorem 16, we can show the following result obtained by Kurokawa and Takahashi [30].

Theorem 17 (Hojo and Takahashi [22]). Let $C$ be a nonempty closed convex subset of a real Hilbert space $H$. Let $T$ be a generalized hybrid mapping of $C$ into itself. Let $u \in C$ and define two sequences $\left\{x_{n}\right\}$ and $\left\{z_{n}\right\}$ in $C$ as follows: $x_{1}=x \in C$ and

$$
\begin{gathered}
x_{n+1}=\alpha_{n} u+\left(1-\alpha_{n}\right) z_{n}, \\
z_{n}=\frac{1}{n} \sum_{k=0}^{n-1} T^{k} x_{n}
\end{gathered}
$$

for all $n=1,2, \ldots$, where $0 \leq \alpha_{n} \leq 1, \alpha_{n} \rightarrow 0$ and $\sum_{n=1}^{\infty} \alpha_{n}=$ $\infty$. If $F(T)$ is nonempty, then $\left\{x_{n}\right\}$ and $\left\{z_{n}\right\}$ converge strongly to $P u \in F(T)$, where $P$ is the metric projection of $H$ onto $A(T)$.

Proof. As in the proof of Theorem 9, a generalized hybrid mapping is a widely more generalized hybrid mapping. Since $\left\{x_{n}\right\},\left\{z_{n}\right\} \subset C$ and $C$ is closed and convex, we have from Theorem 16 that $P u \in A(T) \cap C$. A generalized hybrid mapping with $F(T) \neq \emptyset$ is quasi-nonexpansive, we have from Lemma 7 that $A(T) \cap C=F(T)$. Thus $\left\{x_{n}\right\}$ and $\left\{z_{n}\right\}$ converge strongly to an element $P u \in F(T)$.

\section{Acknowledgments}

Research for Sy-Ming Guu is partially supported by NSC 100-2221-E-182-072-MY2. Wataru Takahashi is partially supported by Grant-in-Aid for Scientific Research no. 23540188 from Japan Society for the Promotion of Science.

\section{References}

[1] W. Takahashi, Introduction to Nonlinear and Convex Analysis, Yokohama Publishers, Yokohama, Japan, 2009.

[2] F. Kohsaka and W. Takahashi, "Fixed point theorems for a class of nonlinear mappings related to maximal monotone operators in Banach spaces," Archiv der Mathematik, vol. 91, no. 2, pp. 166177, 2008.

[3] W. Takahashi, "Fixed point theorems for new nonlinear mappings in a Hilbert space," Journal of Nonlinear and Convex Analysis, vol. 11, no. 1, pp. 79-88, 2010.

[4] S. Iemoto and W. Takahashi, "Approximating common fixed points of nonexpansive mappings and nonspreading mappings in a Hilbert space," Nonlinear Analysis: Theory, Methods and Applications A, vol. 71, no. 12, pp. e2082-e2089, 2009.

[5] W. Takahashi and J.-C. Yao, "Fixed point theorems and ergodic theorems for nonlinear mappings in Hilbert spaces," Taiwanese Journal of Mathematics, vol. 15, no. 2, pp. 457-472, 2011. 
[6] K. Goebel and W. A. Kirk, Topics in Metric Fixed Point Theory, Cambridge University Press, Cambridge, UK, 1990.

[7] W. Takahashi, J.-C. Yao, and F. Kohsaka, "The fixed point property and unbounded sets in Banach spaces," Taiwanese Journal of Mathematics, vol. 14, no. 2, pp. 733-742, 2010.

[8] W. O. Ray, "The fixed point property and unbounded sets in Hilbert space," Transactions of the American Mathematical Society, vol. 258, no. 2, pp. 531-537, 1980.

[9] P. Kocourek, W. Takahashi, and J.-C. Yao, "Fixed point theorems and weak convergence theorems for generalized hybrid mappings in Hilbert spaces," Taiwanese Journal of Mathematics, vol. 14, no. 6, pp. 2497-2511, 2010.

[10] F. Kohsaka and W. Takahashi, "Existence and approximation of fixed points of firmly nonexpansive-type mappings in Banach spaces," SIAM Journal on Optimization, vol. 19, no. 2, pp. 824$835,2008$.

[11] J. B. Baillon, "Un theoreme de type ergodique pour les contractions non lineaires dans un espace de Hilbert," Comptes Rendus de l'Académie des Sciences. Series A-B, vol. 280, pp. 1511-1514, 1975.

[12] W. Takahashi and Y. Takeuchi, "Nonlinear ergodic theorem without convexity for generalized hybrid mappings in a Hilbert space," Journal of Nonlinear and Convex Analysis, vol. 12, no. 2, pp. 399-406, 2011.

[13] L.-J. Lin and W. Takahashi, "Attractive point theorems and ergodic theorems for nonlinear mappings in Hilbert spaces," Taiwanese Journal of Mathematics, vol. 16, no. 5, pp. 1763-1779, 2012.

[14] W. Takahashi, N.-C. Wong, and J.-C. Yao, "Attractive point and weak convergence theorems for new generalized hybrid mappings in Hilbert spaces," Journal of Nonlinear and Convex Analysis, vol. 13, no. 4, pp. 745-757, 2012.

[15] "Existence and mean approximation of fixed points of generalized hybrid mappings in Hilbert spaces," to appear.

[16] S. Banach, "Sur les operations dans les ensembles abstraits et leur application aux equations integrales," Fundamenta Mathematicae, vol. 3, pp. 133-181, 1922.

[17] T. Kawasaki and W. Takahashi, "Fixed point and nonlinear ergodic theorems for new nonlinear mappings in Hilbert spaces," Journal of Nonlinear and Convex Analysis 13, 2012, to appear.

[18] S. Itoh and W. Takahashi, "The common fixed point theory of singlevalued mappings and multivalued mappings," Pacific Journal of Mathematics, vol. 79, no. 2, pp. 493-508, 1978.

[19] Y. Kimura, W. Takahashi, and J. C. Yao, "Strong convergence of an iterative scheme by a new type of projection method for a family of quasinonexpansive mappings," Journal of Optimization Theory and Applications, vol. 149, no. 2, pp. 239-253, 2011.

[20] W. R. Mann, “Mean value methods in iteration," Proceedings of the American Mathematical Society, vol. 4, pp. 506-510, 1953.

[21] T. Shimizu and W. Takahashi, "Strong convergence theorem for asymptotically nonexpansive mappings," Nonlinear Analysis: Theory, Methods and Applications A, vol. 26, no. 2, pp. 265-272, 1996.

[22] M. Hojo and W. Takahashi, "Weak and strong convergence theorems for generalized hybrid mappings in Hilbert spaces," Scientiae Mathematicae Japonicae, vol. 73, no. 1, pp. 31-40, 2011.

[23] W. Takahashi and M. Toyoda, "Weak convergence theorems for nonexpansive mappings and monotone mappings," Journal of Optimization Theory and Applications, vol. 118, no. 2, pp. 417428, 2003.
[24] K. Aoyama, Y. Kimura, W. Takahashi, and M. Toyoda, "Approximation of common fixed points of a countable family of nonexpansive mappings in a Banach space," Nonlinear Analysis: Theory, Methods and Applications A, vol. 67, no. 8, pp. 23502360, 2007.

[25] W. Takahashi, Nonlinear Functional Analysis. Fixed Points Theory and Its Applications, Yokohama Publishers, Yokohama, Japan, 2000.

[26] W. Takahashi, "A nonlinear ergodic theorem for an amenable semigroup of nonexpansive mappings in a Hilbert space," Proceedings of the American Mathematical Society, vol. 81, no. 2, pp. 253-256, 1981.

[27] T. Ibaraki and W. Takahashi, "Weak convergence theorem for new nonexpansive mappings in Banach spaces and its applications," Taiwanese Journal of Mathematics, vol. 11, no. 3, pp. 929-944, 2007.

[28] T. Ibaraki and W. Takahashi, "Fixed point theorems for nonlinear mappings of nonexpansive type in Banach spaces," Journal of Nonlinear and Convex Analysis, vol. 10, no. 1, pp. 21-32, 2009.

[29] T. Shimizu and W. Takahashi, "Strong convergence to common fixed points of families of nonexpansive mappings," Journal of Mathematical Analysis and Applications, vol. 211, no. 1, pp. 7183, 1997.

[30] Y. Kurokawa and W. Takahashi, "Weak and strong convergence theorems for nonspreading mappings in Hilbert spaces," Nonlinear Analysis: Theory, Methods and Applications A, vol. 73, no. 6, pp. 1562-1568, 2010. 


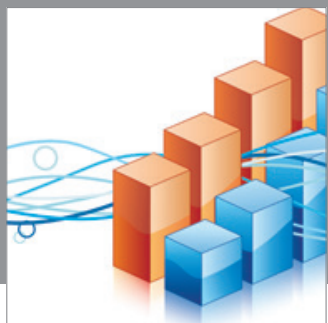

Advances in

Operations Research

mansans

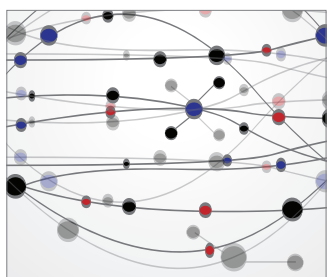

The Scientific World Journal
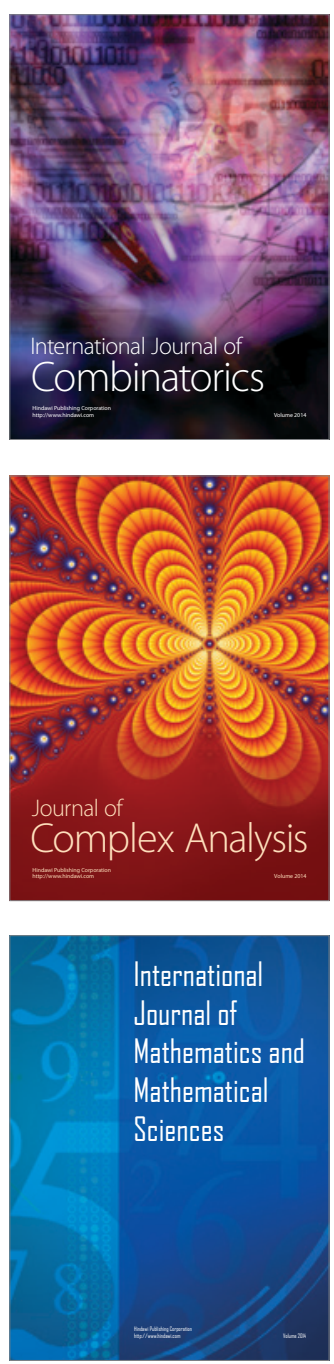
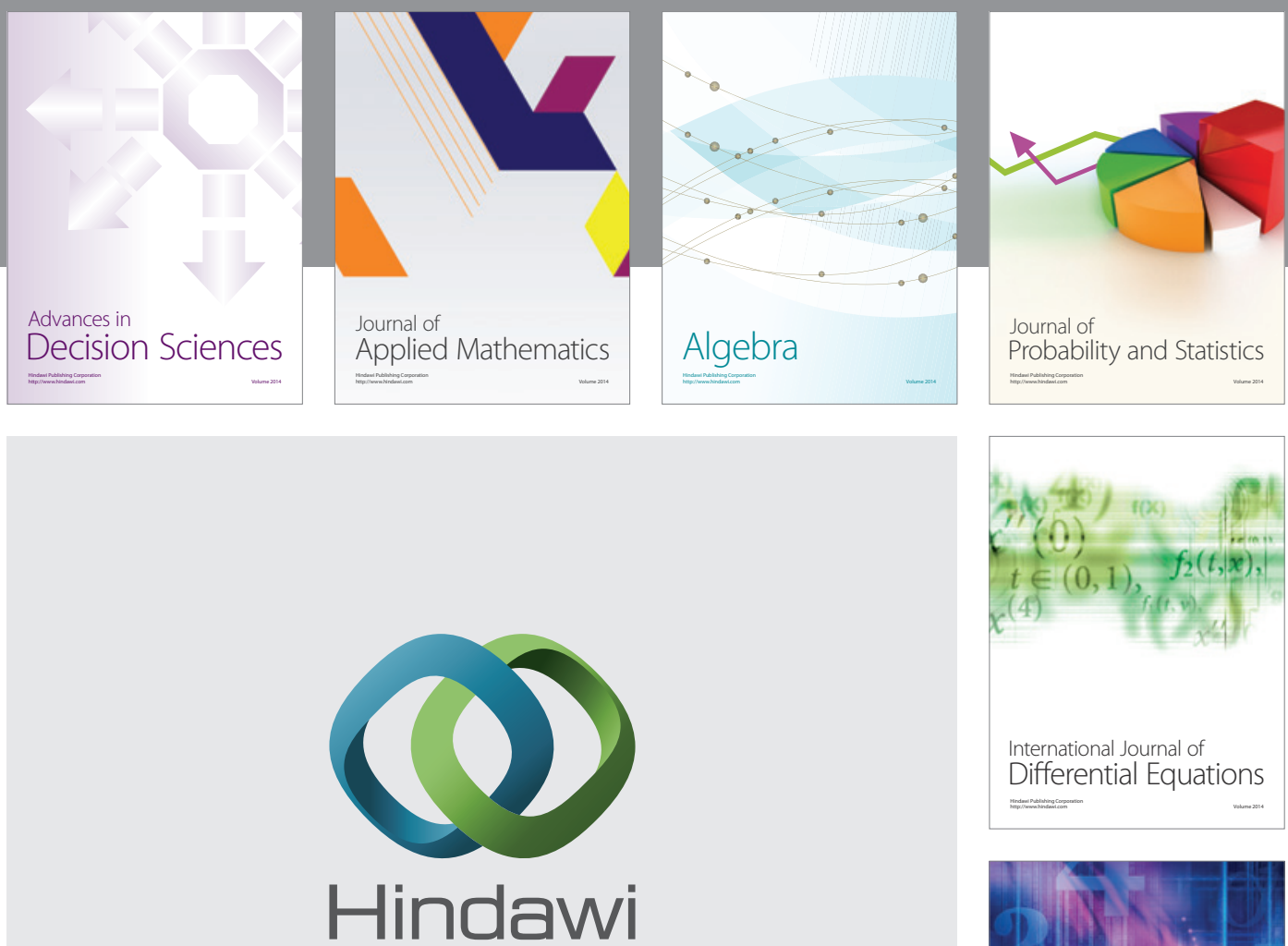

Submit your manuscripts at http://www.hindawi.com
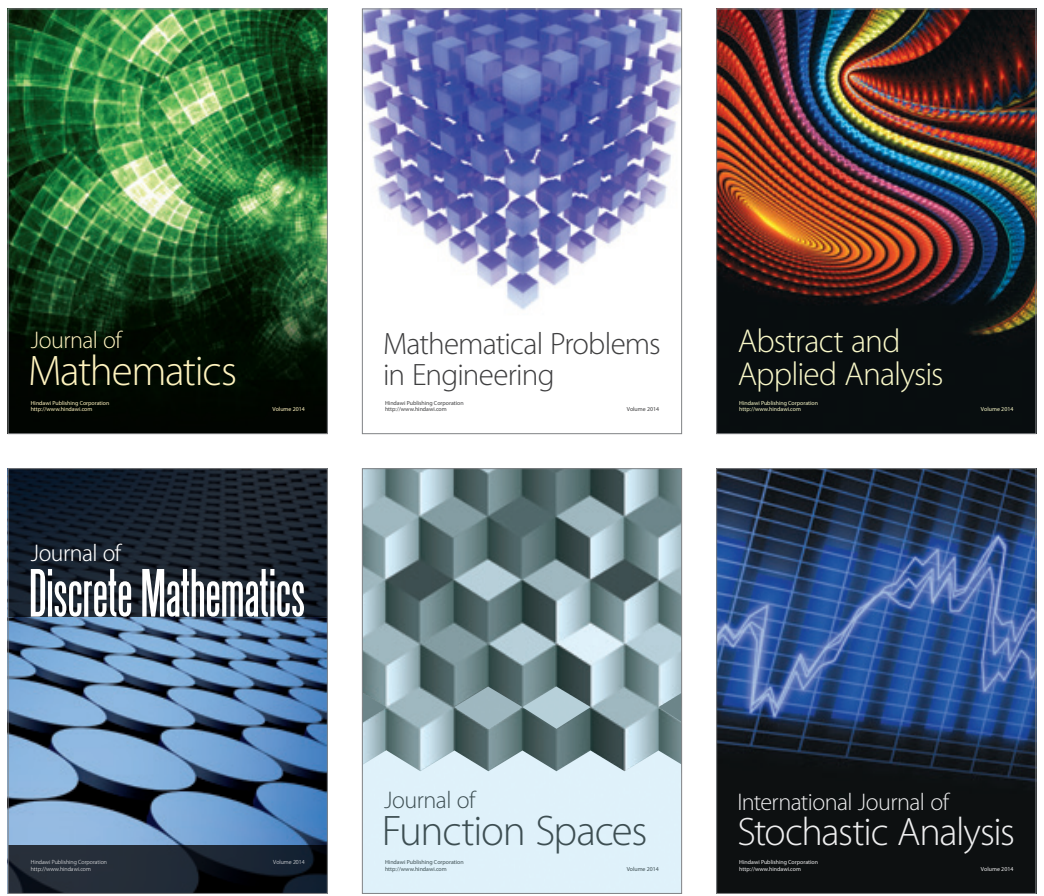

Journal of

Function Spaces

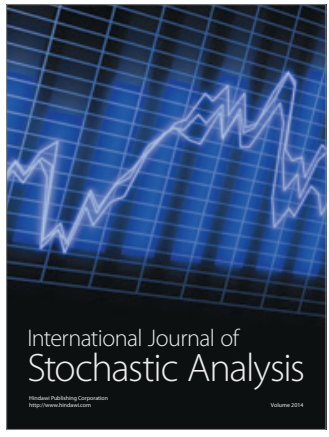

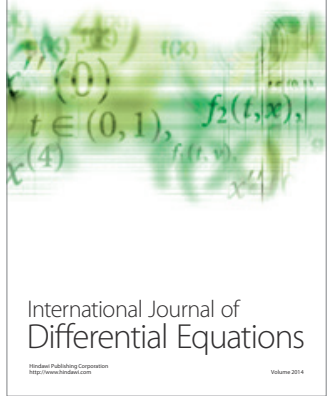
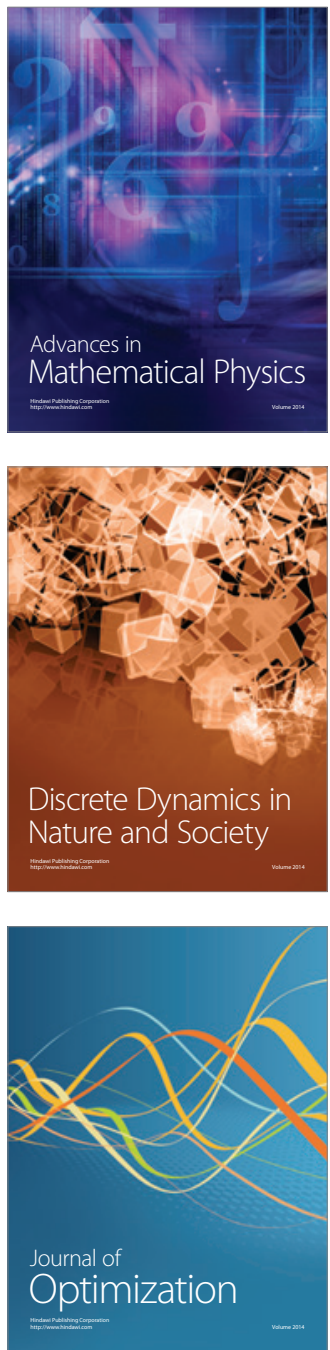